\title{
Familial hyperoxaluria with nephrocalcinosis
}

\author{
S S Vithanage Sukumar ${ }^{1}$, P M G Punchihewa ${ }^{2}$, B J C Perera ${ }^{3}$
}

Sri Lanka Journal of Child Health, 2009; 38: 141-142

(Key words: Familial hyperoxaluria; nephrocalcinosis)

\section{Introduction}

Hyperoxaluria, defined as excessive urinary oxalate excretion, is a common abnormal finding in patients with calcium oxalate kidney stones ${ }^{1}$.

Oxalate is an organic salt with the chemical formula $\mathrm{C}_{2} \mathrm{O}_{4}$. At physiological $\mathrm{pH}$ levels, oxalate forms a soluble salt with sodium and potassium; however, when combined with calcium, it produces an insoluble product termed calcium oxalate, which is the most common chemical compound found in kidney stones. Oxalate increases the solubility product of calcium oxalate crystallization 7 to 10 times more than calcium. Oxalate is normally produced in plants primarily in their leaves, nuts, fruits and the bark and is found in high concentration in tea, coffee, spinach and rhubarb. It is absorbed primarily from the colon, but can be absorbed directly from anywhere in the intestinal tract. In addition, oxalate is created from endogenous sources in liver as a part of glycolate metabolism. In humans oxalates have no substantially beneficial role and act as metabolic end products similar to uric acid.

\section{Case report}

A 2 year old girl from Periyapalam, Muttur was transferred from General Hospital, Trincomalee in May 2003, with a history of polyuria, polydypsia, culture positive urinary tract infection (UTI) diagnosed at the age of $1 \frac{1}{2}$ years and bilateral diffuse nephrocalcinosis detected on ultrasound scan (USS) and micturating cystourethrogram (MCUG).

There was increased frequency both day and night associated with increased thirst. She passed a moderate to large volume of urine but had no dysuria, haematuria or history of passing calculi. She was the product of a consanguineous marriage and there was

\footnotetext{
${ }^{1}$ Senior Registrar in Paediatrics, ${ }^{2}$ Consultant Paediatrician, Lady Ridgeway Hospital, Colombo, ${ }^{3}$ Consultant Paediatrician, Colombo.
}

(Received on 22 September 2008. Accepted on 20 October 2008) no family history of calculi. On examination, both height and weight were below the third centile and there were no features of rickets or chronic renal failure (CRF). There was no acidotic breathing.

On investigation, there was no significant polyuria. A water deprivation test showed partial nephrogenic diabetes insipidus. The x-rays did not show any features of rickets and the parathyroid hormone (PTH) level was normal. There was no acidosis and the anion gap and the acid loading test results were normal. Urinary electrolytes were normal. The urine full report (UFR) showed crystals of calcium oxalate and amorphous phosphates. The 24 hour urinary calcium excretion was normal while the 24 hour oxalate and phosphate excretions were elevated.

Treatment was started with pyridoxine and one week later the urinary oxalate excretion came down from the initial $17.8 \mathrm{mmol} / 24 \mathrm{hrs}$ to $8.4 \mathrm{mmol} / 24 \mathrm{hrs}$ (normal $0.1-3 \mathrm{mmol} / 24 \mathrm{hrs}$ ). At the time of diagnosis serum creatinine was normal but the creatinine clearance was $25 \mathrm{ml} / \mathrm{min} / 1.73 \mathrm{~m}^{2}$. Two months later it was $65 \mathrm{ml} / \mathrm{min} / 1.73 \mathrm{~m}^{2}$.

Five months later, when the USS was repeated at Trincomalee, it showed bilateral medullary calcification with a moderate degree of calyceal dilatation on the right side. From 2003 to 2005 there were several breakthrough infections while on nalidixic acid prophylaxis which was changed to nitrofurantoin with no benefit.

In 2005 May, an USS done at General Hospital, Trincomalee showed a moderate obstructive uropathy with left upper ureteric calculi. She was transferred to the Lady Ridgeway Hospital (LRH) for removal of stones. In the surgical ward the attempted removal of stones failed and the child was transferred to ward 9. USS at LRH showed multiple calculi within the calyces and the parenchyma and pyramids were calcified. The patient passed a stone while in the ward which when analyzed was found to have oxalic acid and calcium. The oxalate excretion at that time was $3.1 \mathrm{mmol} / 24 \mathrm{hrs}$. Pyridoxine dose was increased and the patient was asked to increase the fluid intake. After that several stones were passed with urine. 
When USS was repeated in 2006, there was only nephrocalcinosis and there were no renal calculi or obstruction. Creatinine clearance was $67 \mathrm{ml} / \mathrm{min} /$ $1.73 \mathrm{~m}^{2}$. At this time citric acid and sodium citrate (Bicitra) was added to the treatment. In 2007 April, the oxalate excretion was $3.36 \mathrm{ml} / 24 \mathrm{hrs}$.

In January 2008, her 6 month old younger sister was transferred for investigation of failure to thrive. Her birth weight was $4.5 \mathrm{~kg}$ and the weight on admission was $5.7 \mathrm{~kg}$ which was at the $3^{\text {rd }}$ centile. She was delivered by normal vaginal delivery at term and there were no perinatal complications. There were no significant illnesses and no history of urinary tract infection (UTI) or polyuria. On examination, her weight was at $3^{\text {rd }}$ centile, the height between $10^{\text {th }}-50^{\text {th }}$ centiles and the occipito-frontal circumference (OFC) between $3^{\text {rd }}-10^{\text {th }}$ centiles. On investigation, there was no acidosis and the renal functions were normal. There were no crystals in the UFR and the x-ray abdomen (KUB) was normal. The USS of abdomen showed bilateral nephrocalcinosis with features of chronic renal parenchymal disease. However, her 24 hour oxalate excretion was within normal limits $(1.46 \mathrm{mmol} / 24 \mathrm{hrs})$. Considering the diagnosis of elder sibling and consanguinity a diagnosis of autosomal recessively inherited primary hyperoxaluria was made. She was discharged on pyridoxine to be followed up at General Hospital, Trincomalee with monitoring of renal functions, and we have arranged a review at LRH in 3 months along with her sister and the two other siblings who were never investigated.

\section{Discussion}

There are 3 main types of hyperoxaluria, namely primary hyperoxaluria (Types I and II), enteric hyperoxaluria and idiopathic or secondary hyperoxaluria which is mild.. The secondary hyperoxaluria is by far the most common and may be due to simple dietary excess of high-oxalate food sources and oxalate precursors such as vitamin $\mathrm{C}$ in those with pyridoxine deficiency and in children with intestinal malabsorption ${ }^{2}$. The enteric hyperoxaluria accounts for approximately 5\% of all cases of hyperoxaluria and is due to a gastrointestinal problem usually associated with chronic diarrhoea or malabsorption from any cause. When there is gastrointestinal malabsorption of fatty acids, they bind intraluminal calcium and form salts that are excreted in the faeces. Normally calcium forms a complex with oxalate to reduce oxalate absorption, but if calcium is unavailable, there is increased absorption of unbound oxalate.
Primary hyperoxaluria is a rare but serious disorder caused by a congenital defect resulting in very high endogenous production of oxalate with hyperoxaluria, urolithiasis, nephrocalcinosis and renal injury. Without treatment this variety can cause renal failure in $50 \%$ of patients by age 15 years and in $80 \%$ by age 30 years $^{1}$. Oxalosis, defined as extrarenal deposition of calcium oxalate, occurs when renal insufficiency is present with elevated plasma oxalate $^{2}$. Normal dialysis cannot remove enough serum oxalate to protect the kidneys and other organs from widespread calcium deposition.

There are two types of primary hyperoxaluria. Type I is the more common variety and is transmitted as an autosomal recessive trait. It is caused by a deficiency of the peroxisomal liver specific alanine glyoxylate aminotransferase gene (AGT). Pyridoxine (vitamin $\mathrm{B}_{6}$ ) is a cofactor in this chemical pathway. The median age of presentation of initial symptoms is 5 years. Because symptoms occur relatively late and are associated with serious complications, all paediatric patients who have stones should be screened for hyperoxaluria. Discovering this condition in siblings allows earlier testing, diagnosis and pre-emptive therapy with pyridoxine. Curative treatment involves combined kidney and liver transplantation. The type II is much less common than type I and is due to a deficiency of D-glycerate dehydrogenase which promotes the conversion of glyoxylate to oxalate. End organ renal disease is slightly less common and pyridoxine is generally not effective in this type. There is marked increase in urinary excretion of oxalates in both types and increased urinary excretion of glycolic acid and glyoxylic acid is specific for type I. The presence of L-glyceric acid without increased levels of glycolic and glyoxylic acids in urine differentiates type II from type I. Analysis of stones also help in diagnosis as there is a peculiar morphologic characteristic of stones observed in primary hyperoxaluria which appear to be pathognomonic for that cause, since it was never observed in the patients with other hyperoxaluria states $^{3}$. The diagnosis can be confirmed by an assay of liver enzymes ${ }^{2}$.

A recent study on mice has shown that oral therapy with a crystalline cross-linked formulation of oxalate decarboxylase (OxDc-CLEC) may reduce hyperoxaluria, prevent calcium oxalate nephrocalcinosis and urolithiasis, and can present a realistic option for the treatment of human hyperoxaluria, independent of cause ${ }^{4}$. 


\section{References}

1. Shekariz B. Hyperoxaluria. e-medicine. May 2008. Available from:

http://www.emedicine.com/MED/topic3027.htm

2. Behrman RE, Kliegman RM, Jenson HB, editors, Nelson Text Book of Paediatrics $17^{\text {th }}$ ed. Philadelphia: W B Saunders; 2004. p. 1824.
3. Serrano A, Batlle D. Bilateral Kidney Calcifications New England Journal of Medicine 2008; 359:100-2.

4. Grujic D, Salido EC, Shenoy BC, Langman CB, McGrath ME, Patel RJ, et al. Hyperoxaluria Is Reduced and Nephrocalcinosis Prevented with an Oxalate-Degrading Enzyme in Mice with Hyperoxaluria. Am J Nephrol 2009; 29:86-93. 